Research Paper

\title{
NPAS2 ameliorates myocardial ischaemia/reperfusion injury in rats via CX3CL1 pathways and regulating autophagy
}

\author{
Jing Huang ${ }^{1}$, Wan Qing ${ }^{1}$, Yesheng Pan $^{1}$ \\ ${ }^{1}$ Department of Cardiology, Shanghai East Hospital, Shanghai Tongji University School of Medicine, Shanghai, China
}

Correspondence to: Yesheng Pan; email: felixpan7519@163.com, https://orcid.org/0000-0002-8881-3473

Keywords: myocardial ischemia/reperfusion injury, NPAS2, CX3CL1, autophagy

Received: May 25, $2021 \quad$ Accepted: July 15, $2021 \quad$ Published: August 30, 2021

Copyright: (c) 2021 Huang et al. This is an open access article distributed under the terms of the Creative Commons Attribution License (CC BY 3.0), which permits unrestricted use, distribution, and reproduction in any medium, provided the original author and source are credited.

\begin{abstract}
Background: Myocardial ischemia/reperfusion (I/R) injury is common during the treatment of cardiovascular diseases. Neuronal PAS Domain Protein 2 (NPAS2) is one of the core genes that control the rhythm of the biological clock. NPAS2 also regulates the biological rhythm.

Results: The rat I/R model showed that the expression of NPAS2 decreased with the increase of reperfusion time. Overexpressing NPAS2 adenovirus (ad-NPAS2) was injected into IR rat which demonstrated that adNPAS2 ameliorated rats $I / R$ injury. A hypoxia/reoxygenation (H/R) model in rat cardiomyocytes showed that ad-NPAS2 inhibited cardiomyocyte apoptosis. Co-Immunoprecipitation results showed that there is an interaction between NPAS2 and Cry2. Knockdown of Cry2 aggravated the cardiomyocyte apoptosis induced by $H / R$. Additionally, NPAS2 directly act on the promoter region of CX3CL1. Knockdown of CX3CL1 reverse the protective effect of ad-NPAS2 on rat myocardial ischemia-reperfusion injury and H/R-induced cardiomyocyte apoptosis. CX3CL1 also regulates autophagy through the downstream AKT/mTOR pathway.

Conclusions: research demonstrated that overexpression of NPAS2 interacts with Cry2 and promotes the transcriptional activity of CX3CL1. Moreover, overexpression of NPAS2 regulates the downstream AKT/mTOR pathway to inhibit autophagy in order to improve rat cardiac I/R injury.
\end{abstract}

\section{INTRODUCTION}

Cardiovascular disease (CVD) is the main cause of death with a mortality rate higher than that of tumors and other diseases. CVD morbidity and mortality rate have been increasing yearly [1]. Acute myocardial infarction (AMI) is the most fatal among ischemic heart diseases [2,3]. Currently, CVD is treated through blood reperfusion as early as possible. Therefore, recovering coronary blood supply early is the basic treatment for acute myocardial infarction [4, 5]. However, reperfusion is a double-edged sword [6]. Reperfusion causes additional cardiomyocyte damage while preserving the original ischemic cardiomyocytes. The main manifestations of reinjury include myocardial function, morphology and alteration in metabolism and other aspects that can induce cardiomyocyte death in severe cases [7]. The pathogenesis of myocardial ischemia/reperfusion injury is a complex process involving multiple factors comprised of many molecular and cellular mechanisms. The exact mechanism has not yet been fully elucidated [8]. Studies have shown that the main factors for pathogenesis of myocardial ischaemia/reperfusion injury include the accumulation of oxygen free radicals, calcium ion overload, mitochondrial dysfunction, inflammation, endothelial cell damage, apoptosis and autophagy and other mechanisms $[9,10]$. Based on the research of these mechanisms, most of the current drug treatments have been developed for pathogenesis. These include scavenging free radicals and antioxidant therapy, reducing calcium ion overload, inhibiting cardiomyocyte apoptosis, ischemic preconditioning, etc. [11]. However, even though a large number of 
experiments with definite curative effects have been published in the journals, no positive results have been obtained in relation to clinical applications [12, 13]. There is no effective method to avoid or reduce myocardial ischemia reperfusion injury.

Myocardial ischemia/reperfusion injury stimulate the body's endogenous protective mechanisms to repair myocardial damage, such as activating autophagy, antiinflammatory, and apoptosis inhibitory signals [14]. Autophagy is a cellular process that participates in the degradation of damaged or redundant proteins and organelles. Autophagy plays a role in regulating cell homeostasis and maintaining body energy [15]. Autophagy is a protective intracellular process. Recently, studies have shown that when moderate autophagy plays enhances cell viability and inhibits cell apoptosis. However, when autophagy is over-activated or maintained at a high level, it causes self-digestion and the degradation of the basic components in the cell which ultimately leads to impaired tissue and organ function [16]. Autophagy also plays an important role in the process of myocardial ischemia and reperfusion. In the myocardial ischemia stage, autophagy is activated due to the energy crisis of myocardial cells and oxidative stress. This helps to maintain the structure and function of myocardial cells and protect the physiological functions of the heart. In the reperfusion stage, autophagy is over-activated, it causes autophagic death of cardiomyocytes and tissue damage [14]. Moreover, autophagy affects the level of cardiomyocyte apoptosis through the Beclin $1 / \mathrm{Bcl}-2$ pathway, and aggravate cardiomyocyte damage [17]. Therefore, autophagy has become a major area for studying the mechanism of drugs that protect myocardial I/R injury.

The circadian clock is internal in the organism and is synchronized with the circadian time. This ensures that the body can adjust its activities and physiological responses to adapt to changes in the surrounding environment at different times of the day. The molecular composition of the circadian clock is very complex. A series of core circadian genes form a negative feedback loop through transcription and translation which causes circadian rhythm changes. There are 10 cloned core biological rhythm genes including NPAS2 in the chromosomes [18]. Theodore et al. found that, the circadian clock gene oscillation (that is, the difference from peak to trough) in the I/R area rapidly weakened compared with the non-ischemic area [19]. A report in Circ Res. showed that the heart was ischemic during the transition from sleep to waking (ZT12). The infarct area increased by 3.5 times compared with the infarct area (in the ischaemic heart) during the transition from waking to sleep (ZT0). After 1 month of reperfusion, the ischemic events of ZT12 compared to ZT0 resulted in greater infarct volume, fibrosis, poor remodeling, and greater inhibition of contractile function [20]. NPAS2 is an important member of the biorhythm gene family. It is widely distributed in human tissues and cells, and it mainly functions as a transcription factor in the cell [21]. The study also found that, the expression of the circadian clock gene NAPS2 in the I/R area was down-regulated compared with the non-ischemic area [19]. Whether NPAS2 regulates autophagy to contribute to its function in cardiomyocytes ischemia/reperfusion, little is known about it. Hence, the purpose of this research was to clarify the effect of NPAS2 in modulating autophagy caused by ischemia/reperfusion and its potential mechanisms.

\section{RESULTS}

\section{NPAS2 was downregulated in of myocardial ischaemia/reperfusion injury rats}

The changes in the morphology of myocardial tissues were detected using $\mathrm{HE}$ and Masson staining. The results showed that fibrosis of myocardial tissues was intensified gradually in $30 \mathrm{~min}$ ischaemia heart as a consequence of $60 \mathrm{~min}$ and $180 \mathrm{~min}$ reperfusion (Figure 1A, 1B). Moreover, M-mode echocardiographic analyses, TTC and Tunel staining indicated that, myocardial infarction size and apoptotic myocytes were increased. Additionally, Left ventricular ejection fraction (LVEF) was decreased after ischaemia followed by $60 \mathrm{~min}$ and $180 \mathrm{~min}$ reperfusion (Figure 1C-1H). qRT-PCR and Western blot results demonstrated that NPAS2 mRNA and protein expression were suppressed after $30 \mathrm{~min}$ ischaemia and further decreased after $60 \mathrm{~min}$ and $180 \mathrm{~min}$ reperfusion (Figure 1I, 1J). Western blot tests the protein of LC3B and p62 which indicated that $I / R$ enhanced cardiomyocyte autophagy n (Figure 1J). In summary, the data revealed the connotation between the level of NPAS2, autophagy and ischaemia/reperfusion injury.

\section{Overexpression of NPAS2 ameliorated rats ischaemia/reperfusion injury in vivo and hypoxia/reoxygenation injury in vitro}

Rats were intratracheally administered with overexpressing NPAS2 adenovirus (ad-NPAS2) and knockdown NPAS2 adenovirus (shNPAS2) for two consecutive days once a day to further elucidate the mechanism of NPAS2. ad-NPAS2 and shNPAS2 induced myocardial ischaemia for 30 minutes and reperfusion for 180 minutes. The histomorphology of the cardiac muscle and M-mode echocardiographic analyses indicated that ad-NPAS2 regulated I/R induced myocardial damage while shNPAS2 exacerbated myocardial damage (Figure 2A-2H). The qRT-PCR and 


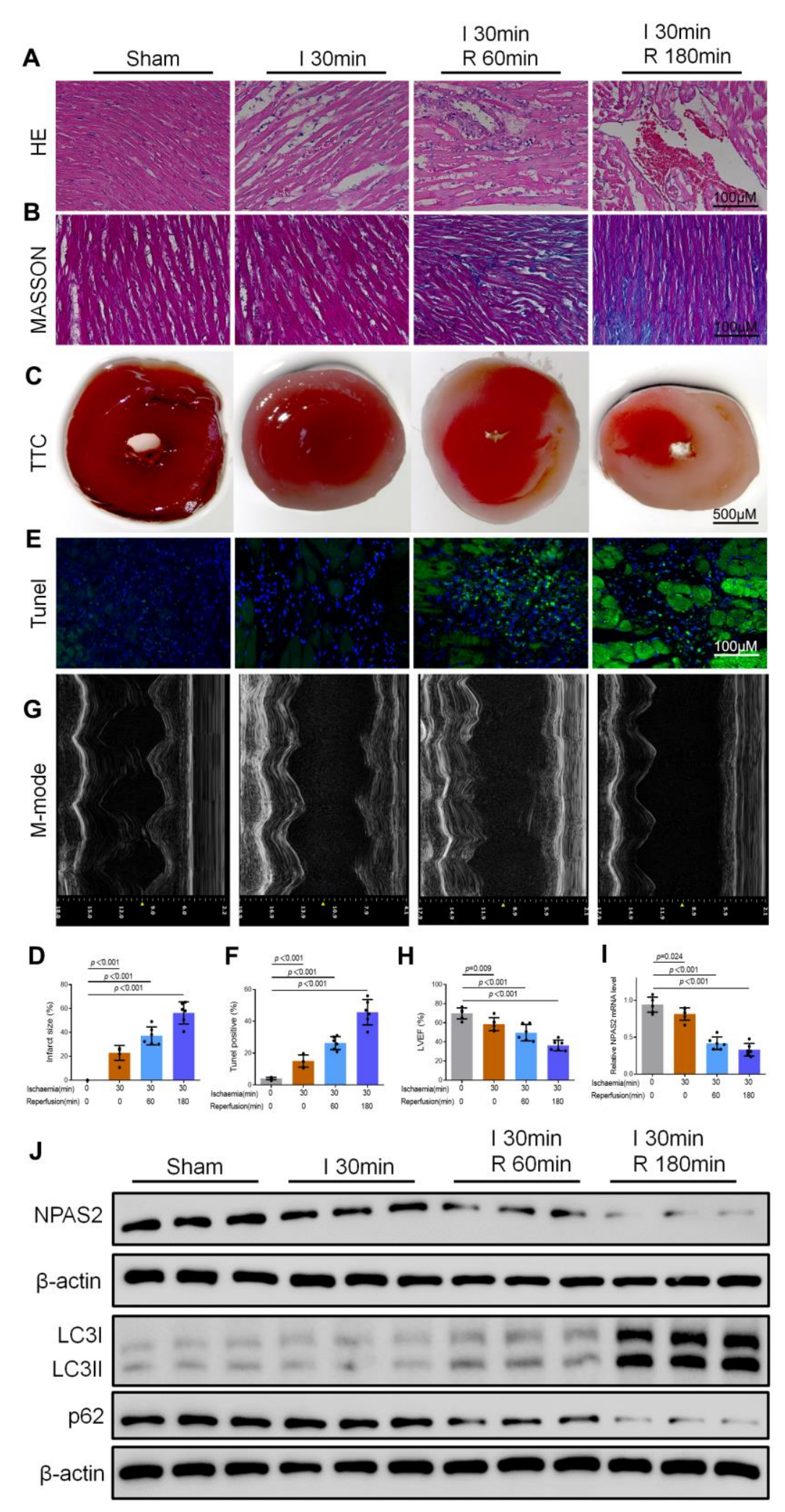

Figure 1. NPAS2 was downregulated in myocardial ischaemia/reperfusion injury rats. (A, B) Typical images of H\&E and Masson staining of myocardial tissue segments. (C, D) Typical images of TTC of myocardial tissue segments. The infarct size was measured and calculated as a percentage of the total area. (E, F) Typical images of Tunel of myocardial tissue segments. The relative percentages of apoptotic cells were calculated. (G, H) Typical echocardiographic images of M-mode and LVEF. (I) The mRNA level of NPAS2 in rat myocardial tissue was determined by qRT-PCR. (J) The protein level of NPAS2 (90kDa), LC3B (14 and 16kDa) and p62 (62kDa) in rat myocardial tissue was determined using Western Blot. Data are expressed as mean $\pm \operatorname{SEM}(n=6)$. 


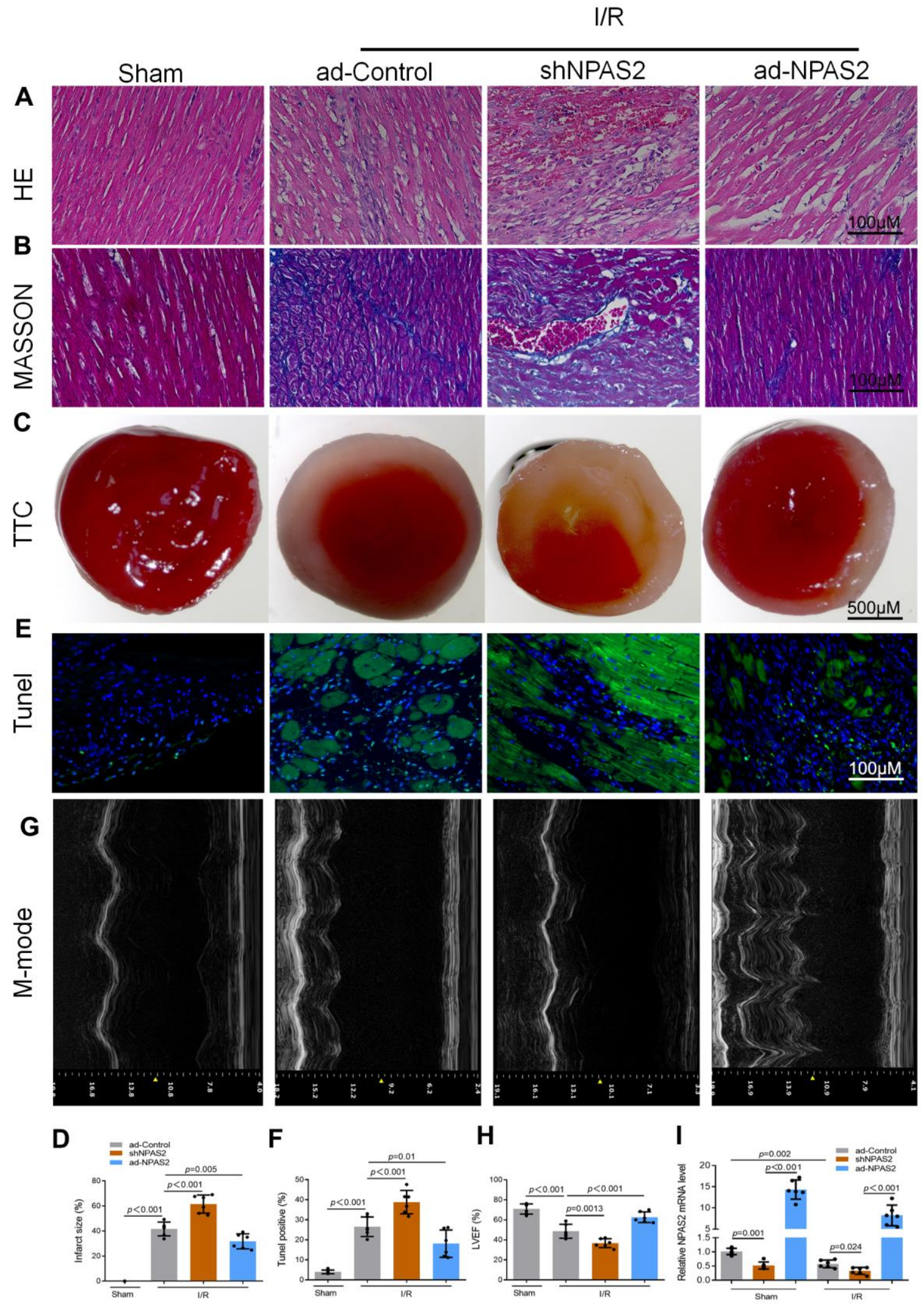

Figure 2. Overexpression of NPAS2 ameliorated rats ischaemia/reperfusion injury in vivo. (A, B) Typical images of H\&E and Masson staining of myocardial tissue segments. (C, D) Typical images of TTC of myocardial tissue segments. The infarct size was measured and calculated as a percentage of the total area. (E, F) Typical images of Tunnel of myocardial tissue segments. The relative percentages of apoptotic cells were calculated. (G, H) Typical echocardiographic images of M-mode and LVEF. (I) The mRNA level of NPAS2 in rat myocardial tissue was determined by qRT-PCR. Data are expressed as mean $\pm \operatorname{SEM}(n=6)$. 
Western blot assay proved the transfection efficiency of ad-NPAS2 and shNPAS2 in myocardial tissue (Figures 2I, 3A). Figure 3B revealed that the level of cleavedcaspase 3 rose after ad-NPAS2 reversed its expression while shNPAS2 exacerbated its expression. Additionally, Western blot results of LC3B and p62, and immunofluorescence assay of LC3B (green) indicated that ad-NPAS2 suppressed I/R induced cardiomyocyte autophagy while shNPAS2 aggregated cardiomyocyte autophagy (Figure 3C, 3D).

The ad-NPAS2 and shNPAS2 was transfected into a hypoxia/reoxygenation model on rat cardiomyocytes H9c2 for $48 \mathrm{~h}$. The rat cardiomyocytes H9c were exposed to hypoxia $6 \mathrm{~h}$ and reoxygenation for $18 \mathrm{~h}$. Moreover, in vivo $\mathrm{I} / \mathrm{R}$ studies, flow cytometry and Western blot result of cleaved-caspase 3 showed that adNPAS2 inhibited cardiomyocyte apoptosis while shNPAS2 exacerbated cardiomyocyte apoptosis (Figure 4A-4C). Western blot assay verified the transfection efficiency of ad-NPAS2 and shNPAS2 in H9c2 cells (Figure 4D). Western blot results of LC3B and p62 indicated H/R induced autophagy in H9c2 cells. LC3-II/I level was suppressed and p62 level rose after transfection with ad-NPAS2 (Figure 4E). Furthermore, mRFP-GFP-LC3 revealed the increase of autolysosomes (RFP) and autophagosomes (RFP) in $\mathrm{H} 9 \mathrm{c} 2$ cells after
H/R, and suppressed with ad-NPAS2 (Figure 4F). Results of Transmission electron microscopy (TEM) of autophagic vacuoles in $\mathrm{H} 9 \mathrm{c} 2$ cells were consisted with mRFP-GFP-LC3 results (Figure 4G).

\section{Cry2 interacted with NPAS2 in cardiomyocyte}

Cryptochrome circadian regulator 2 (Cry2) is a core circadian gene [22]. Bioinformatics analysis predicted Cry2 and NPAS2 have a potential interaction relationship (Figure 5A, 5B). Western blot assay showed that overexpression of NPAS2 enhanced the level of Cry2, while inhibition of NPAS2 suppressed the level of Cry2 both in vivo and in vitro (Figure 5C). Coimmunoprecipitation (co-IP) results indicated NPAS2 and Cry 2 formed a protein complex in myocardial tissue and $\mathrm{H} 9 \mathrm{c} 2$ cells. It was immunoprecipitation with antiNPAS2 or anti-Cry2 antibodies which were detected using anti-Cry2 or anti-NPAS2 (Figure 5D). Moreover, Cry2 knockdown adenovirus was transfected into H9c2 cells. Flow cytometry and Western blot result of cleaved-caspase 3 showed that the silence of Cry2 reversed the anti-apoptosis effect of NPAS2 (Figure 5E5G). Western blot results and immunofluorescence staining of NPAS2 (green) and Cry2 (red) further confirmed the interaction between NPAS2 and Cry 2 and their co-localization in H9c2 cells (Figure 5H, 5I).

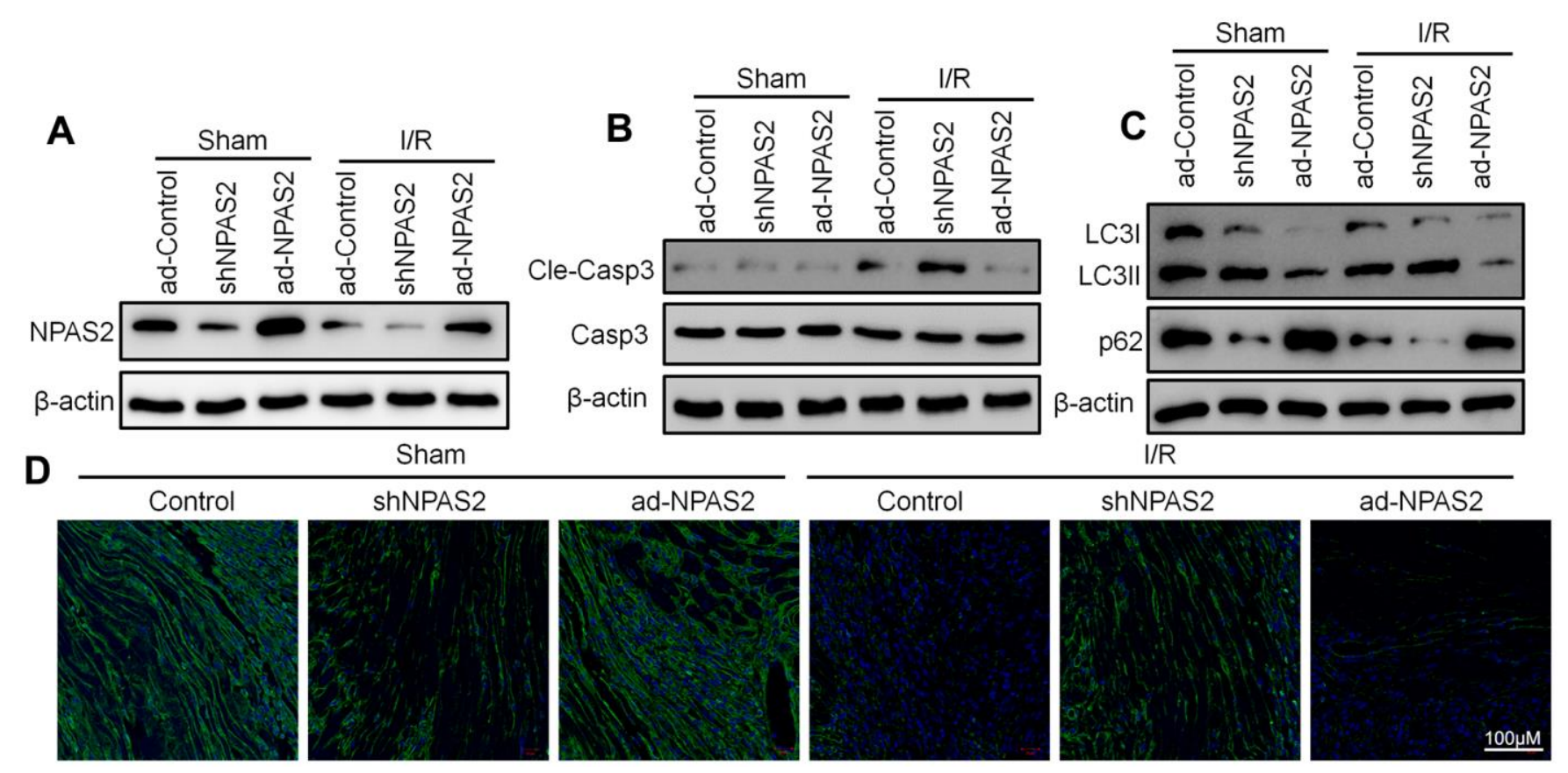

Figure 3. Overexpression of NPAS2 inhibited autophagy in ischaemia/reperfusion injury rats. (A) The protein level of NPAS2 in rat myocardial tissue was determined using Western Blot. (B) The protein level of Cleaved-Caspase-3 (17kDa) and Caspase-3 17kDa) in rat myocardial tissue was determined by Western Blot. (C) The protein level of LC3B and p62 in rat myocardial tissue was determined using Western Blot. (D) Representative photomicrographs of LC3B (green) immunofluorescence in rat myocardial tissue. DAPI was used to counterstain nuclei. 


\section{NPAS2 transcriptionally promoted CX3CL1 expression in cardiomyocyte}

Yi et al. found that CX3CL1 is the direct transcriptional targets of NPAS2 in breast cancer cells via using the genome-wide ChIP-on-chip analysis [23]. Western blot results revealed that ad-NPAS2 promoted CX3CL1 expression. shNPAS2 inhibited CX3CL1 expression both in vivo (Figure 6A) and in vitro (Figure 6B). Luciferase assay confirmed that CX3CL1 was the transcriptional target of NPAS2 (Figure 6C). ChIP assay confirmed that NPAS2 binds directly to the CX3CL1
A

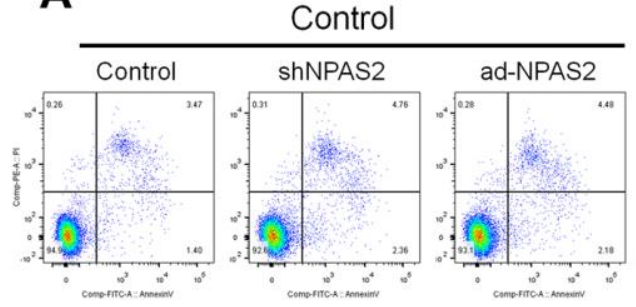

C

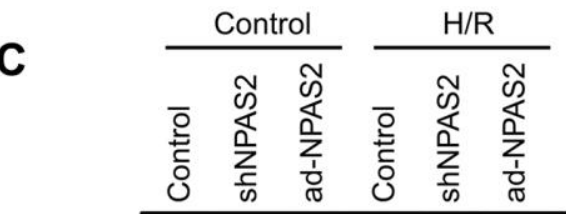

Cle-Casp3 $\cdots \cdots \cdots$

Casp3

$\beta$-actin

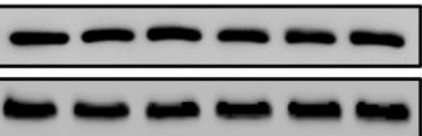

GFP
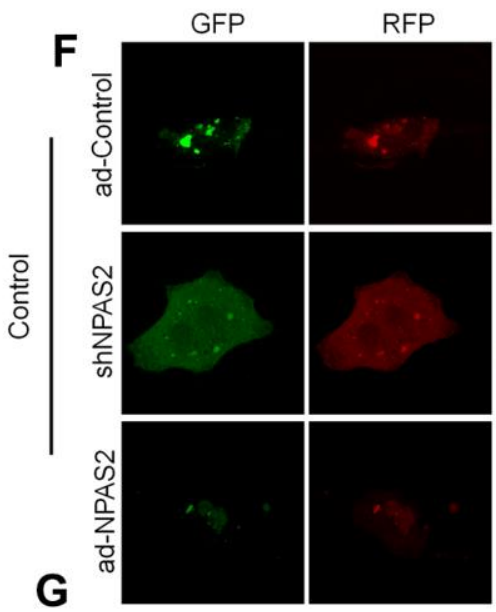

Merg

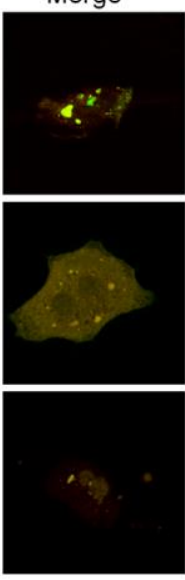

Control

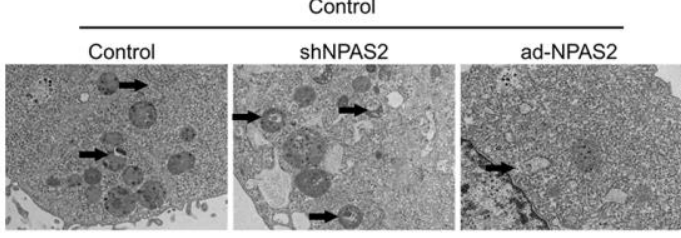

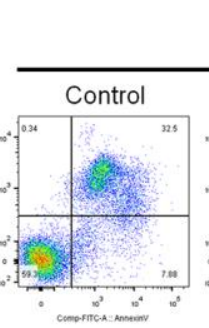

$H / R$
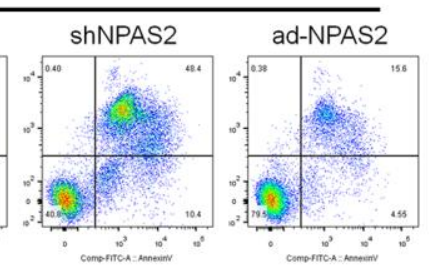

B

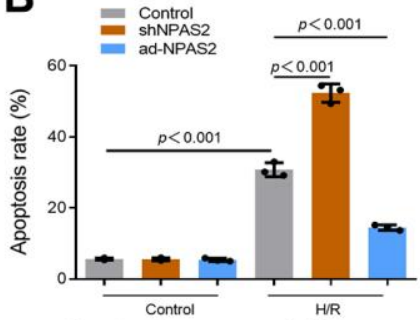

D<smiles>[CH-]C</smiles>
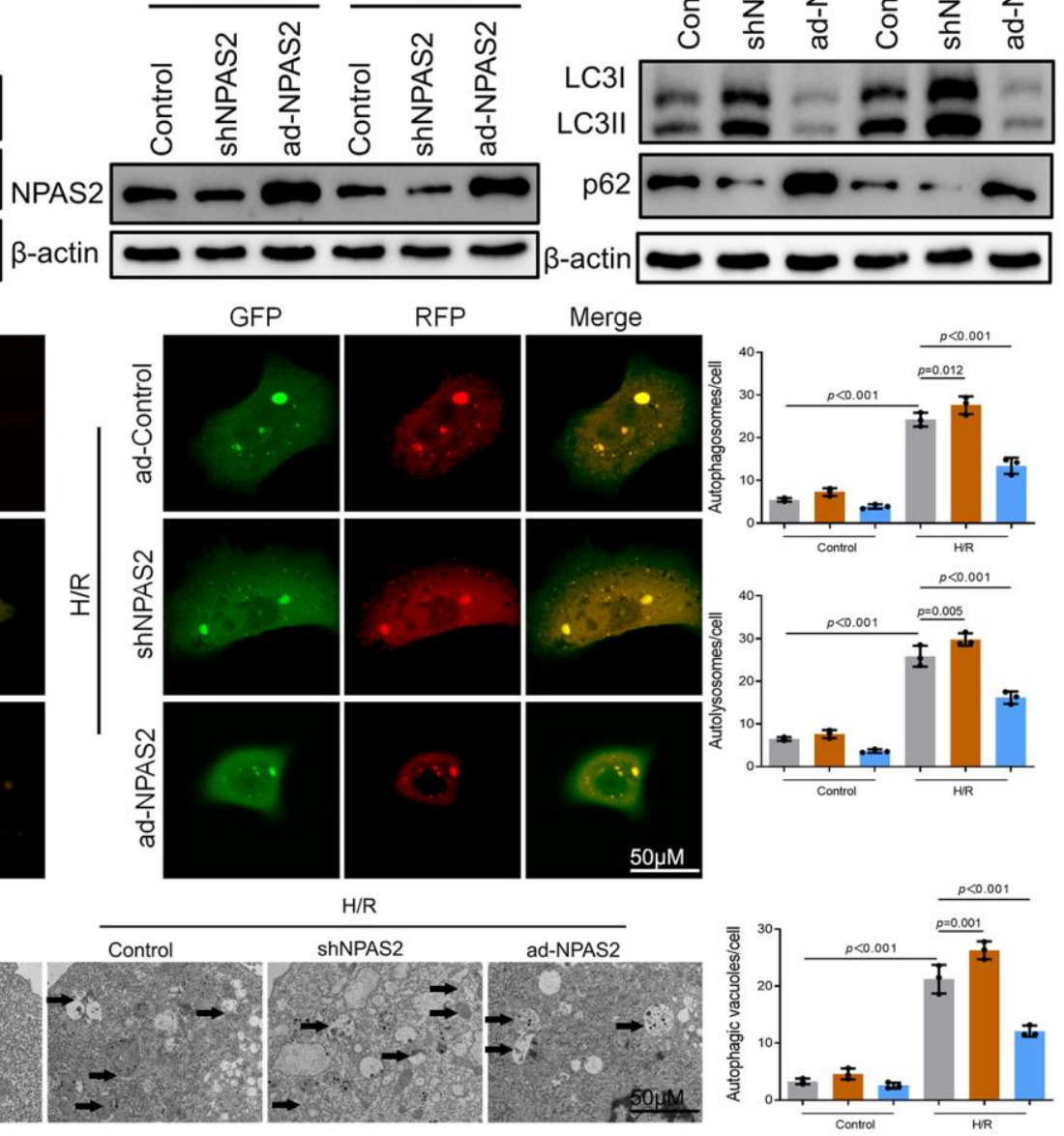

Figure 4. Overexpression of NPAS2 ameliorated hypoxia/reoxygenation injury in vitro. (A, B) Flow cytometry detected the changes of apoptosis in H9c2 cells and quantified. (C) The protein level of Cleaved-Caspase-3 (17kDa) and Caspase-3 (17kDa)in H9c2 cells was determined by Western Blot. (D) The protein level of NPAS2 in H9c2 cells was determined by Western Blot. (E) The protein level of LC3B (14 and $16 \mathrm{kDa})$ and p62 $(62 \mathrm{kDa})$ in H9c2 cells was determined by Western Blot. (F) Typical images of immunofluorescence staining of mRFP-GFPLC3 in H9c2 cells. Typical profiles of autophagosomes (RFP+GFP+dots) and autolysosomes (RFP+GFP-dots). (G) Autophagic vacuoles (autophagosomes) determined by transmission electron microscopy (TEM). Representative TEM images are shown, and typical autophagosomes are marked with black arrows. Data are expressed as mean $\pm \operatorname{SEM}(n=3)$. 

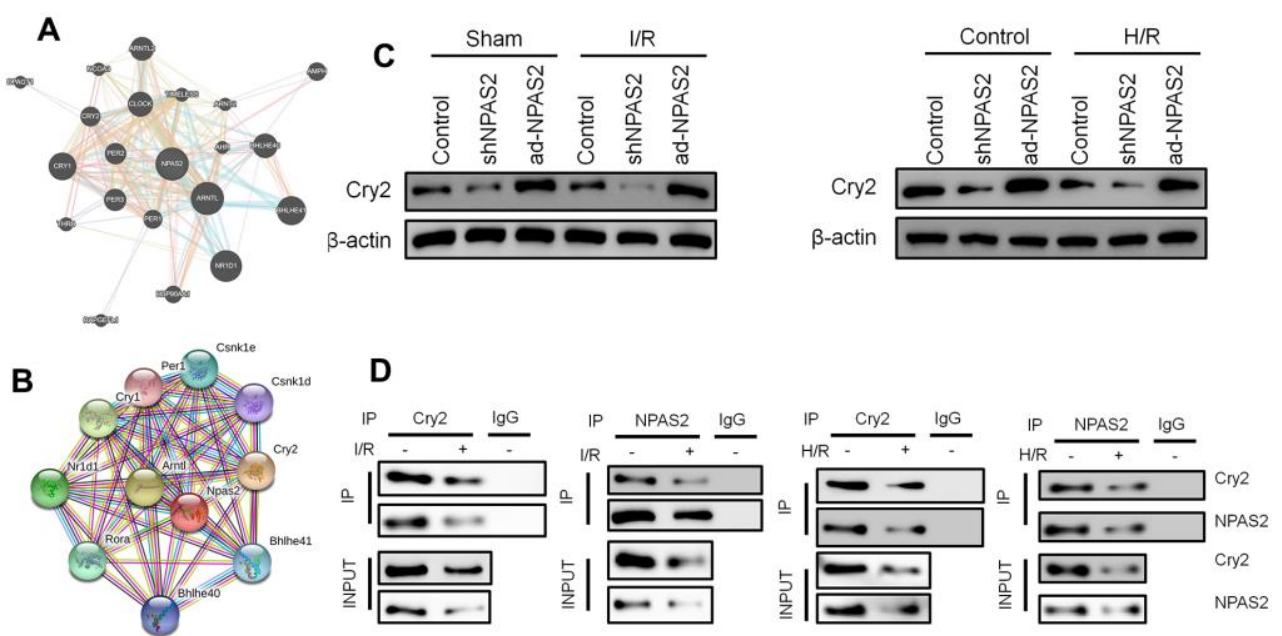

E
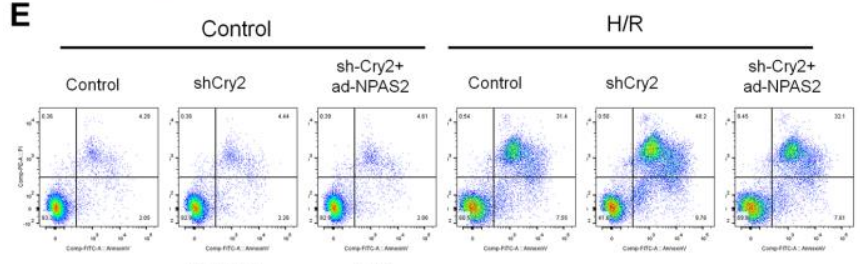

$\mathbf{F}$

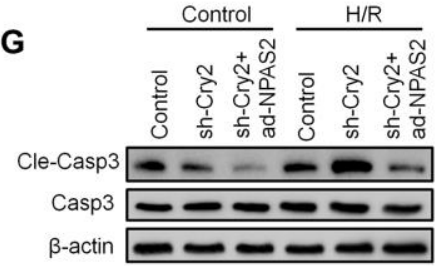

H H Control
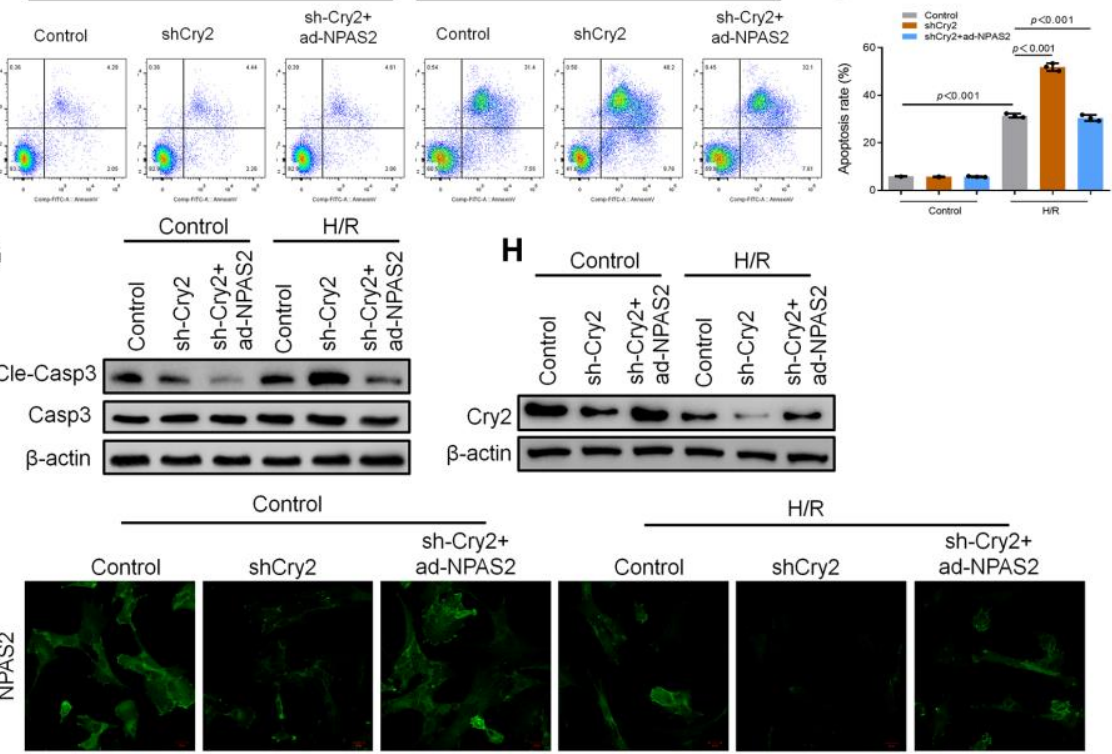

Control
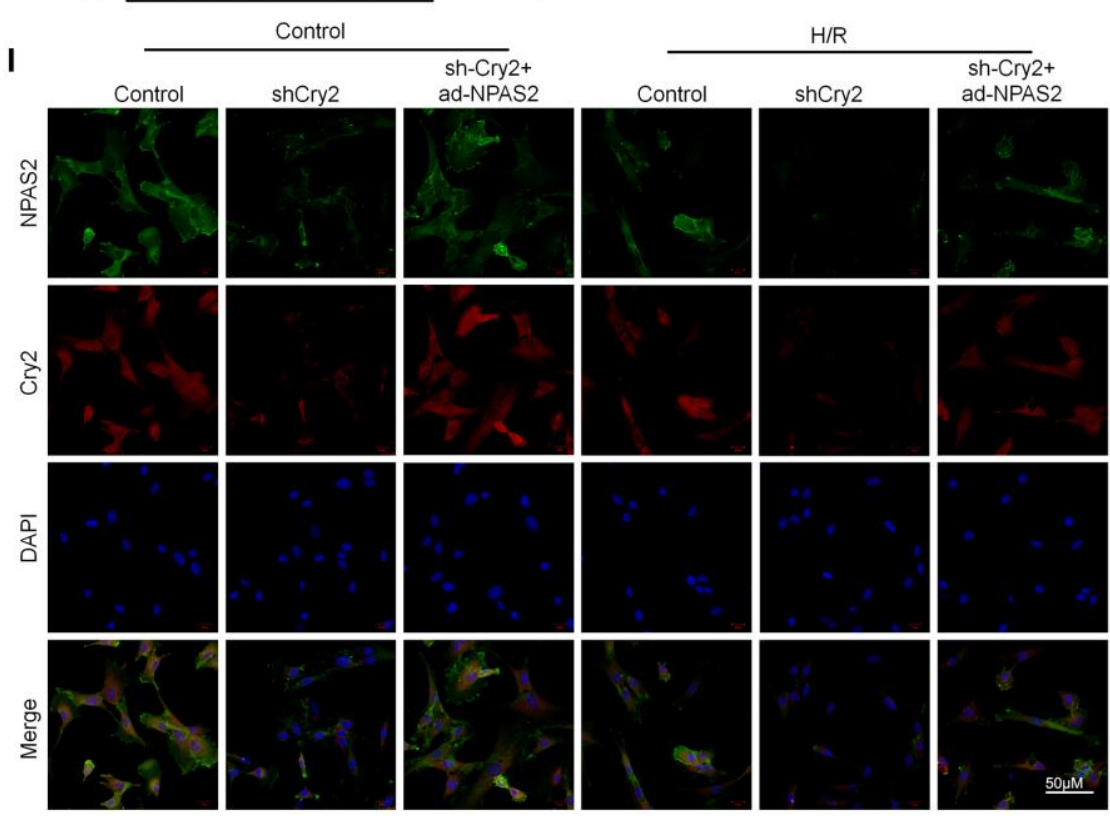

Figure 5. Cry2 interacted with NPAS2 in cardiomyocyte. (A, B) String database (https://string-db.org/) and BioGRID Database (biogrid.org) were used to predict Cry2 and NPAS2 interaction. (C) The protein level of Cry2 (67kDa) in rat myocardial tissue and H9c2 cells was determined using Western Blot. (D) Co-IP assay was performed with anti-NPAS2 or anti-Crry2 antibody was carried out using extracts prepared from rat myocardial tissue and H9c2 cells. The presence of Cry2 or NPAS2 in these IPs was determined using Western Blot. (E, F) Flow cytometry detected the changes of apoptosis in H9c2 cells and quantified. (G) The protein level of Cleaved-Caspase-3 (17kDa) and Caspase-3 (17kDa) in H9c2 cells was determined using Western Blot. (H) The protein level of NPAS2 (90kDa) in H9c2 cells was determined using Western Blot. (I) Representative photomicrographs of NPAS2 (green) and Cry2 (Red) immunofluorescence in H9c2 cells. DAPI was used to counterstain nuclei. Data are expressed as mean $\pm \operatorname{SEM}(n=3)$. 

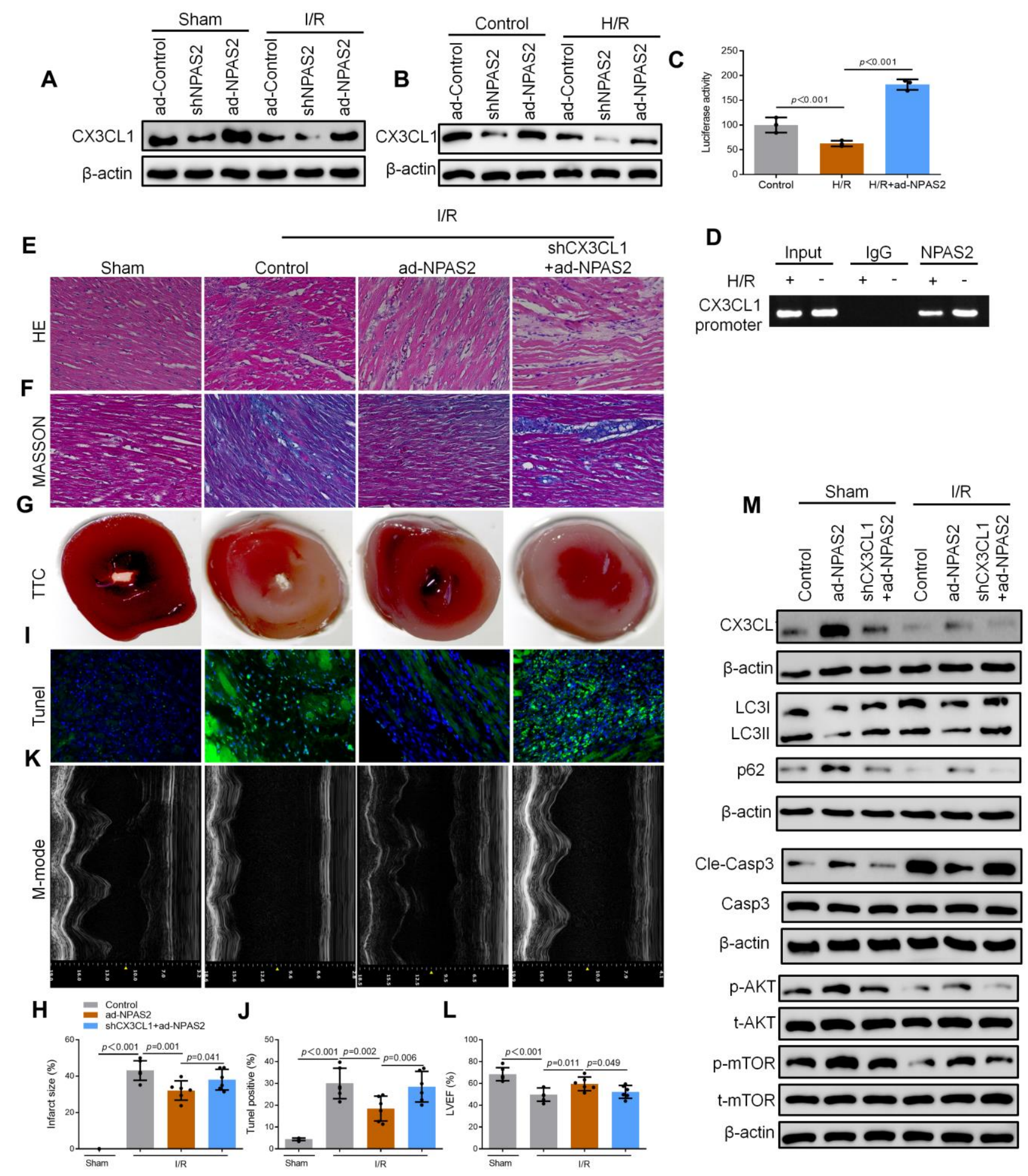

Figure 6. NPAS2 transcriptionally promoted CX3CL1 expression in vivo. (A) The protein level of CX3CL1 (100kDa) in rat myocardial tissue was determined by Western Blot. (B) The protein level of CX3CL1 (100kDa) in H9c2 cells was determined by Western Blot. (C) H9c2 cells were transfected with CX3CL1 promoter and the luciferase activity was determined after 24 hours. (D) Amplification of the CX3CL1 promoter sequence was performed BY ChIP assay in H9c2 cells. (E, F) Typical images of H\&E and Masson staining of myocardial tissue segments. (G, H) Typical images of TTC of myocardial tissue segments. The infarct size was measured and calculated as a percentage of the total area. (I, J) Typical images of Tunnel of myocardial tissue segments. The relative percentages of apoptotic cells were calculated. (K, L) Typical echocardiographic images of M-mode and LVEF. (M) The protein level of CX3CL1 (100kDa), LC3B (14 and $16 \mathrm{kDa})$, p62 (62kDa), Cleaved-Caspase-3 (17kDa), Caspase-3 (17kDa), p-AKT (60kDa), t-AKT (60kDa), p-mTOR (289kDa) and t-mTOR (289kDa) in rat myocardial tissue was determined by Western Blot. Data are expressed as mean $\pm \operatorname{SEM}(n=6)$. 
promoter region in $\mathrm{H} 9 \mathrm{c} 2$ cells. Knockdown CX3CL1adenovirus (shCX3CL1) was administered intratracheally into rats followed by ad-NPAS2 to further explore the mechanism of CX3CL1. The histomorphology of the cardiac muscle and M-mode echocardiographic analyses showed that, inhibition of CX3CL1 reversed the therapeutic effect of ad-NPAS2 against I/R induced myocardial injury in rats (Figure $6 \mathrm{E}-6 \mathrm{~L})$. A study reported that CX3CL1 enhanced the phosphorylation of AKT in acute myelocytic leukemia cells [24]. AKT/mTOR pathway is involved in regulating of autophagy $[25,26]$. The AKT/mTOR pathway was evaluated using western blot. The data showed that I/R suppressed the phosphorylation of AKT and mTOR. The data also showed that overexpression of NPAS2 promoted the phosphorylation of AKT and mTOR. However, the effect of ad-NPAS2 was suppressed by shCX3CL1 (Figure 6M). Moreover, shCX3CL1 suppressed autophagy in myocardial tissue.

shCX3CL1 was transfected into H9c2 cells for $48 \mathrm{~h}$. Flow cytometry and Western blot result of cleavedcaspase 3 showed that shCX3CL1 promoted cardiomyocyte apoptosis which was inhibited by adNPAS2 (Figure 7A-7C). Western blot verified that the level of CX3CL1 rose due to overexpression of NPAS2 and was suppressed by silence of CX3CL1 in H9c2 cells (Figure 7D). Figure 7E, 7F revealed that NPAS2 promoted the phosphorylation of AKT and mTOR while was suppressed by shCX3CL1. Western blot results of LC3B and p62 indicated shCX3CL1 inhibited autophagy via AKT/mTOR pathway in $\mathrm{H} 9 \mathrm{c} 2$ cells. mRFP-GFP-LC3 and TEM results in H9c2 cells were consisted with Western blot results (Figure 7G, 7H).

\section{DISCUSSION}

The study was designed to determine the mechanism of NPAS2 in myocardial ischaemia/reperfusion injury. The abnormality of the circadian gene, NPAS2, is closely related to various diseases. Studies showed that NPAS2 is closely related to many diseases. Englund et al. found that the SNP rs11541353 of NPAS2 is closely related to hypertension which is one of the risk factors of metabolic syndrome [27]. People with the minor allele of SNP rs11541353 of NPAS2 have a low risk of hypertension. NPAS2 was closely associated with fetal liver metabolism and non-alcoholic fatty liver disease. Changes in fetal liver metabolism in NPAS2 knockout mice were mainly concentrated in lipid metabolism compared with wild-type mice. The possible underlying mechanism was related to the increase of PGC1 $\alpha$ after NPAS2 knockout [28]. In addition, NPAS2 plays an important regulatory role in acquiring specific types of memory [29]. Gene variants of NPAS2 are related to winter depression [30,31], reproduction and seasonal changes [32], and chronic fatigue syndrome [33]. Zhu et al. found that the non-synonymous mutation SNP rs2305160 (Ala394Thr) of NPAS2 is associated with the risk of non-Hodgkin's lymphoma [34]. Hoffman et al. found that decreased expression of NPAS2 regulates the expression of multiple genes related to cell cycle and apoptosis [35]. This is related to the function of the NPAS2 transcription factor, and interference with NPAS2 can cause cells to react abnormally damaging DNA while damaging DNA repair capabilities. Therefore, NPAS2 play a role in inhibiting the occurrence and development of cells by regulating the expression of genes related to DNA damage. In this study, the results revealed that the enhanced level of NPAS2 during I/R contributed to cardiomyocyte apoptosis. These results confirmed the findings of a great deal of the previous work. However, several researches have reported that NPAS2 is an oncogene. Yuan et al. found that the expression of NPAS2 in liver cancer tissues was significantly down-regulated [36]. Clinicopathological analysis showed that the expression of NPAS2 in liver cancer correlated with tumor size, TNM stage and distant metastasis. In addition, the 5year survival rate of patients in the high expression group of NPAS2 was significantly lower than that in the low expression group. In this research, rats were injected with NPAS2 overexpression adenovirus which lead to the increased expression of NPAS2 in whole body of rats. The effect of such long-term use on the carcinogenicity of rats is unknown. Hence, cardiac specific NPAS2-Tg rat or cardiac specific adenoassociated virus (AAV) should be used for further studies to observe the specific effect of NPAS2 on heart tissue.

CX3CL1 is also known as fractalkine. CX3CL1 is the only known cell-membrane binding chemokine. It act both as chemokines and adhesion molecules concurrently. Membrane-bound CX3CL1 is mainly expressed on the surface of endothelium and epithelial cells. Membrane-bound CX3CL1 mainly mediate adhesion and plays a role in capturing neutrophils with positive expression of CX3CR1 in the bloodstream. The free state CX3CL1 mainly act as chemokines, chemokines to monocytes, natural killer cells, dendritic cells and $\mathrm{T}$ cells, etc. [37]. CX3CL1 is expressed in different cells where it plays different roles. CX3CL1 expression in lymphocyte induces adhesion. CX3CL1 mediates chemotaxis in mesenchymal cells. CX3CL1 also participate in the process of tumor immune cells infiltration and invasion [38]. CX3CL1 exerts its antiinflammatory effects by reducing neurotoxicity and suppressing the overexpression of inflammatory factors (IL-1 $\beta$, IL-6, TNF- $\alpha$ ). Co-culture of neuron-microglia cells CX3CL1 reduce the production of proinflammatory cytokines induced by lipopolysaccharide 
and reduce the apoptosis of inflammation-related neurons [39]. In clinical studies, serum levels of CX3CL1 is associated with cardiovascular diseases such as carotid artery stenosis [40], unstable angina pectoris [41], and systolic heart failure [42]. The research results clearly indicated that the level of CX3CL1 was significantly decreased by I/R injury. The data also showed that NPAS2 transcriptionally upregulates CX3CL1 expression and inhibition of CX3CL1 reversed the treatment of ad-NPAS2 both
A

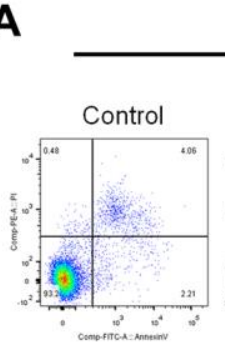

Control

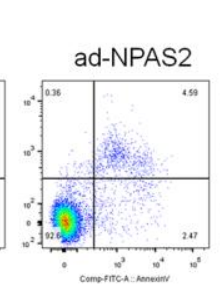

C

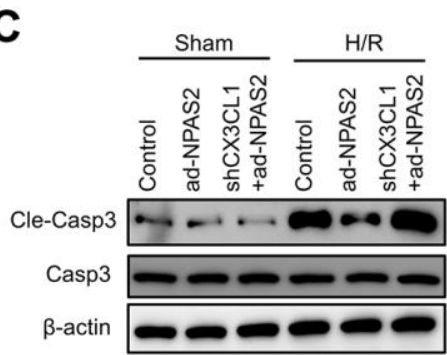

D

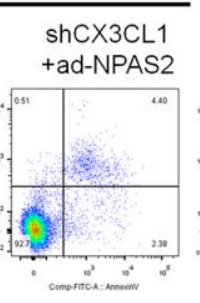

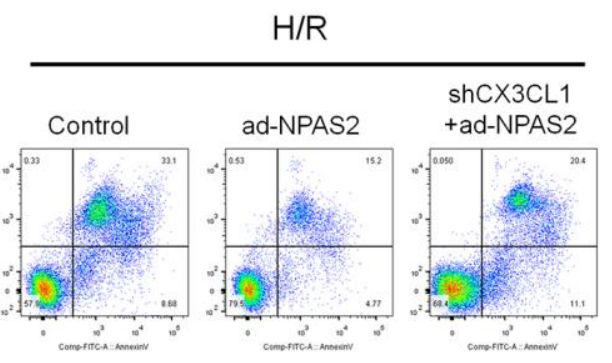

E

Sham

$H / R$
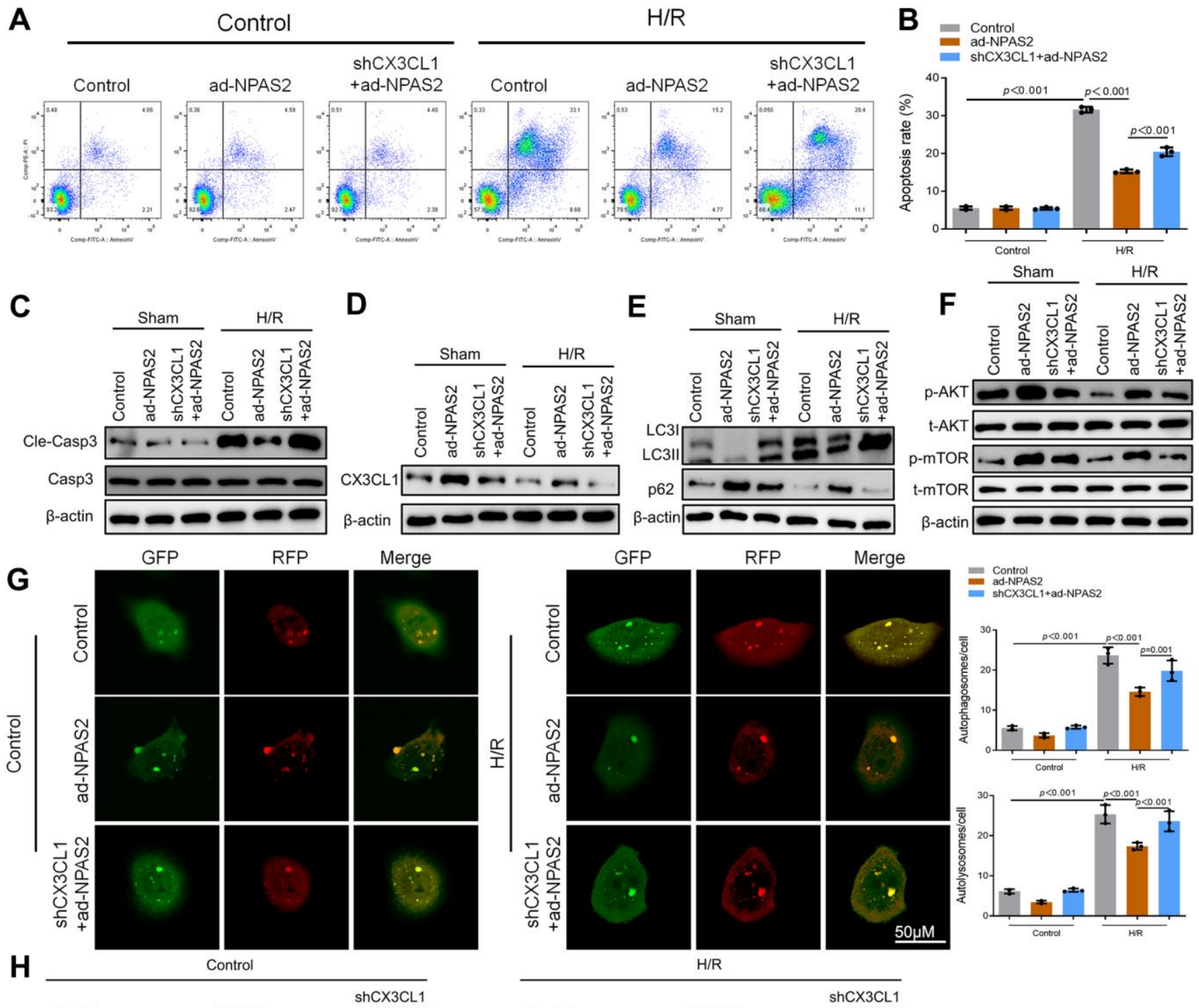

LC3II
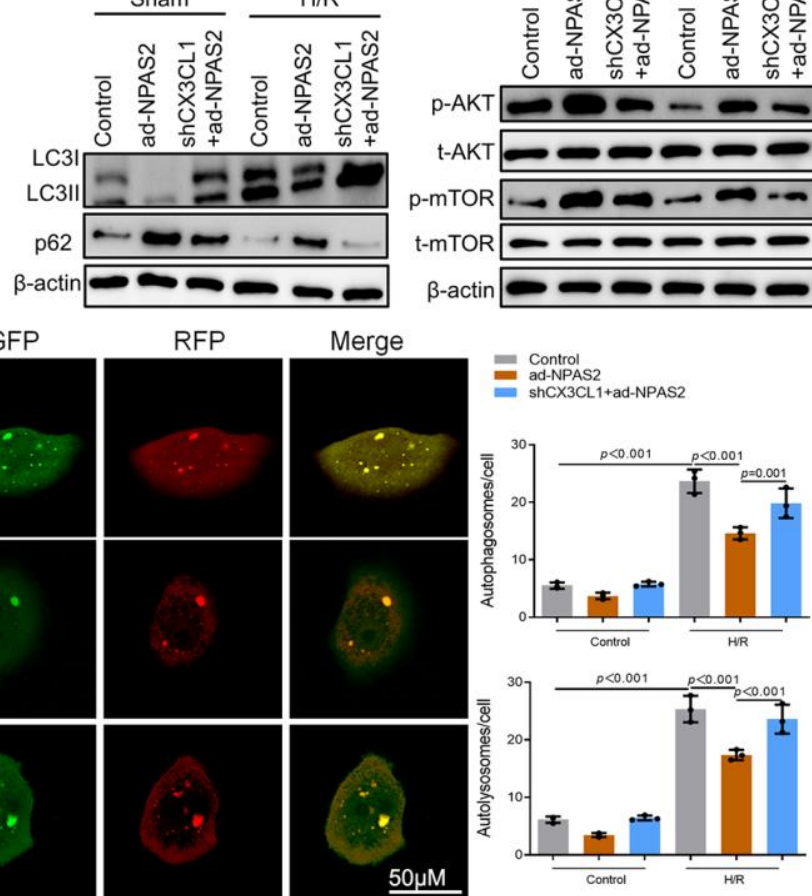

Control

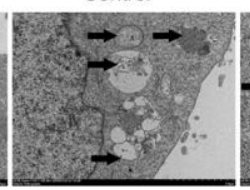

ad-NPAS2
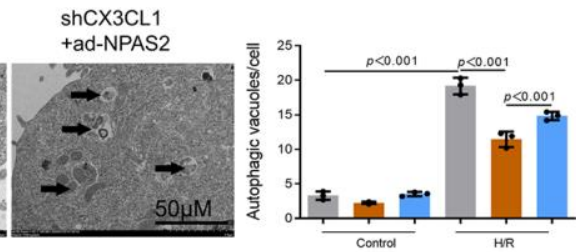

Figure 7. NPAS2 transcriptionally promoted CX3CL1 expression in vitro. (A, B) Flow cytometry detected the changes of apoptosis in H9c2 cells and quantified. (C) The protein level of Cleaved-Caspase-3 (17kDa) and Caspase-3 (17kDa) in H9c2 cells was determined by Western Blot. (D) The protein level of CX3CL1 (100kDa) in H9c2 cells was determined by Western Blot. (E) The protein level of LC3B (14 and $16 \mathrm{kDa})$ and p62 (62kDa) in H9c2 cells was determined by Western Blot. (F) The protein level of p-AKT (60kDa), t-AKT (60kDa), p-mTOR $(289 \mathrm{kDa})$ and t-mTOR (289kDa) in H9c2 cells was determined by Western Blot. (G) Typical images of immunofluorescence staining of mRFPGFP-LC3 in H9c2 cells. Typical profiles of autophagosomes (RFP+GFP+dots) and autolysosomes (RFP+GFP-dots). (H) Autophagic vacuoles (autophagosomes) determined by transmission electron microscopy (TEM). Representative TEM images are shown, and typical autophagosomes are marked with black arrows. Data are expressed as mean \pm SEM $(n=3)$. 
in vitro and in vivo. More exploration on the mechanism of CX3CL1 in vascular endothelium and its effect on $\mathrm{I} / \mathrm{R}$ in future experiments should be done. This is based on the fact that membrane-bound CX3CL1 is mainly expressed on the surface of endothelial and epithelial cells. Moreover, in this article, promoter activity of CX3CL1 was measured with a luciferase assay. Serial deletion and site-directed mutagenesis analyses were used to confirm the directly binding site in the CX3CL1 promoter region.

In this paper, NPAS2 was identified to regulate autophagy in a CX3CL1/AKT-dependent manner. High levels of NPAS2 inhibited autophagy and suppressed cardiomyocytes apoptosis. Researchers have found an association between AKT/mTOR mediated autophagy and myocardial ischemia/reperfusion injury [43-45]. However, studies also showed that Beclin1-mediated autophagy is involved in myocardial ischemia/ reperfusion injury. Zhu et al. found that, inhibition of Beclin1 expression in cardiomyocytes resulted in decreased autophagy and apoptosis of cardiomyocytes induced by $\mathrm{I} / \mathrm{R}$ [46]. The mechanism is that ROS induced Beclin1 upregulation leading to defect in autophagosome maturation and increasing cell death [47]. It is unknown whether NPAS2 regulated the activation of autophagy via Beclin1. More research on this topic needs to be undertaken before the association between NPAS2 and Beclin1 is clearly understood in myocardial I/R injury.

\section{CONCLUSIONS}

The findings clearly indicate that overexpression of NPAS2 interacts with Cry2 and promotes the transcriptional activity of CX3CL1 NPAS2 also regulates the downstream $\mathrm{AKT} / \mathrm{mTOR}$ pathway to inhibit autophagy to ameliorated rat cardiac I/R injury in vitro and in vivo. These results propose an opportunity that NPAS2 could be a potential target in acute myocardial infarction.

\section{MATERIALS AND METHODS}

\section{Animals and ethics statement}

Male Sprague-Dawley rats (180-230 g) were purchased from Shanghai Sippr Bk Laboratory Animals (Shanghai, China). All rats were given free access to food and water under controlled conditions $(12 / 12 \mathrm{~h}$ light/dark cycle with humidity of $60 \% \pm 5 \%$ and a temperature of $22^{\circ} \mathrm{C} \pm 3^{\circ} \mathrm{C}$ ). All animals were treated in accordance with the Guidelines for Care and Use of Laboratory Animals. All experiments were approved and performed according to the guidelines of the Ethics Committee of Shanghai East Hospital, Shanghai, China.
All surgical procedures were performed under anesthesia, and every effort was made to minimize suffering. Rats were anesthetized by intraperitoneal injection of sodium pentobarbital $(30 \mathrm{mg} / \mathrm{kg})$.

\section{Myocardial I/R model}

Rats were anaesthetized with 1-2\% isoflurane. Myocardial ischaemia was induced by temporarily exteriorizing the heart via a left thoracic incision while placing a silk suture (6-0) slipknot around the left anterior descending coronary artery. After $30 \mathrm{~min}$ myocardial infarction, the slipknot was released, and the myocardium was reperfused. A subset of animals was treated with either MnTMPyP (5 mg/kg ip, $30 \mathrm{~min}$ before surgery) or sodium chloride (saline). Shamoperated control rats (sham) underwent the same surgical procedures except that the suture placed under the left anterior descending was not tied. Anaesthesia was maintained with isoflurane inhalation and rat were sacrificed by cutting the carotid artery after $60 \mathrm{~min}$ or 180min reperfusion. Each group contained 6 different rats/group.

\section{Cell lines and cell culture}

The rat cardiomyoblast cell line $\mathrm{H} 9 \mathrm{c} 2$ was purchased from the American Type Culture Collection (ATCC, Manassas, VA, USA) and cultured in DMEM supplemented with $10 \%$ FBS. H9c2 cells was transfected with the ad-NPAS2, shNPAS2, shCry2 or shCX3CL1 adenovirus for $48 \mathrm{~h}$ before exposure to hypoxia $(93 \% \mathrm{~N} 2,2 \% \mathrm{O} 2$, and $5 \% \mathrm{CO} 2)$ for $6 \mathrm{~h}$ and reoxygenation for $18 \mathrm{~h}$. The $\mathrm{H} 9 \mathrm{c} 2$ cells were then harvested for biological analyses.

\section{Statistical analysis}

All data were expressed as the mean \pm standard error of the mean (SEM). Significant differences in mean were evaluated using One-Way ANOVA accompanied by LSD post hoc tests for mean separation. The significance level was set at $\mathrm{P}<0.05$.

Detailed information on materials and methods is shown in the Supplementary Methods.

\section{Ethics approval and consent to participate}

The animal study has been examined and certified by the Ethics Committee of Shanghai East Hospitals.

\section{Availability of data and materials}

The datasets generated for this study are available on request to the corresponding authors. 


\section{AUTHOR CONTRIBUTIONS}

$\mathrm{JH}$ and WQ performed research and analyzed results. $\mathrm{JH}$ and YP discussed results and edited the paper. YP designed research. $\mathrm{JH}$ and $\mathrm{YP}$ wrote the paper, and supervised the study. All authors read and approved the final manuscript.

\section{ACKNOWLEDGMENTS}

We thank HOME for Researchers (http://www.homefor-researchers.com/static/index.html\#/retouch_draw) for editing this manuscript.

\section{CONFLICTS OF INTEREST}

The authors declare that they have no conflicts of interest.

\section{FUNDING}

This work was supported by the Top-level Clinical Discipline Project of Shanghai Pudong District (No. PWYgf2018-02).

\section{REFERENCES}

1. Ueshima H, Sekikawa A, Miura K, Turin TC, Takashima N, Kita Y, Watanabe M, Kadota A, Okuda N, Kadowaki T, Nakamura Y, Okamura T. Cardiovascular disease and risk factors in Asia: a selected review. Circulation. 2008; 118:2702-09.

https://doi.org/10.1161/CIRCULATIONAHA.108.79004 8 PMID:19106393

2. Sanchis-Gomar F, Perez-Quilis C, Leischik R, Lucia A. Epidemiology of coronary heart disease and acute coronary syndrome. Ann Transl Med. 2016; 4:256. https://doi.org/10.21037/atm.2016.06.33 PMID:27500157

3. Reynolds K, Go AS, Leong TK, Boudreau DM, CassidyBushrow AE, Fortmann SP, Goldberg RJ, Gurwitz JH, Magid DJ, Margolis KL, McNeal CJ, Newton KM, Novotny $R$, et al. Trends in Incidence of Hospitalized Acute Myocardial Infarction in the Cardiovascular Research Network (CVRN). Am J Med. 2017; 130:317-27.

https://doi.org/10.1016/j.amjmed.2016.09.014 PMID:27751900

4. Anderson JL, Morrow DA. Acute Myocardial Infarction. N Engl J Med. 2017; 376:2053-64. https://doi.org/10.1056/NEJMra1606915 PMID:28538121

5. Heusch G, Gersh BJ. The pathophysiology of acute myocardial infarction and strategies of protection beyond reperfusion: a continual challenge. Eur Heart J. 2017; 38:774-84.

https://doi.org/10.1093/eurheartj/ehw224

PMID:27354052

6. Neri M, Riezzo I, Pascale N, Pomara C, Turillazzi E. Ischemia/Reperfusion Injury following Acute Myocardial Infarction: A Critical Issue for Clinicians and Forensic Pathologists. Mediators Inflamm. 2017; 2017:7018393.

https://doi.org/10.1155/2017/7018393

PMID:28286377

7. Takemura G, Kanoh M, Minatoguchi S, Fujiwara H. Cardiomyocyte apoptosis in the failing heart--a critical review from definition and classification of cell death. Int J Cardiol. 2013; 167:2373-86.

https://doi.org/10.1016/j.ijcard.2013.01.163 PMID:23498286

8. Turer AT, Hill JA. Pathogenesis of myocardial ischemiareperfusion injury and rationale for therapy. Am J Cardiol. 2010; 106:360-68. https://doi.org/10.1016/j.amjcard.2010.03.032 PMID:20643246

9. Ferdinandy $P$, Schulz R, Baxter GF. Interaction of cardiovascular risk factors with myocardial ischemia/reperfusion injury, preconditioning, and postconditioning. Pharmacol Rev. 2007; 59:418-58. https://doi.org/10.1124/pr.107.06002 PMID:18048761

10. Marczin N, El-Habashi N, Hoare GS, Bundy RE, Yacoub M. Antioxidants in myocardial ischemia-reperfusion injury: therapeutic potential and basic mechanisms. Arch Biochem Biophys. 2003; 420:222-36. https://doi.org/10.1016/j.abb.2003.08.037 PMID:14654061

11. Frank A, Bonney M, Bonney S, Weitzel L, Koeppen M, Eckle T. Myocardial ischemia reperfusion injury: from basic science to clinical bedside. Semin Cardiothorac Vasc Anesth. 2012; 16:123-32.

https://doi.org/10.1177/1089253211436350 PMID:22368166

12. Ibáñez B, Heusch G, Ovize M, Van de Werf F. Evolving therapies for myocardial ischemia/reperfusion injury. J Am Coll Cardiol. 2015; 65:1454-71. https://doi.org/10.1016/j.jacc.2015.02.032 PMID:25857912

13. Hausenloy DJ, Yellon DM. Preconditioning and postconditioning: new strategies for cardioprotection. Diabetes Obes Metab. 2008; 10:451-59. https://doi.org/10.1111/j.1463-1326.2007.00762.x PMID:17825079

14. Matsui Y, Takagi $H, Q u X$, Abdellatif $M$, Sakoda $H$, Asano T, Levine B, Sadoshima J. Distinct roles of autophagy in the heart during ischemia and 
reperfusion: roles of AMP-activated protein kinase and Beclin 1 in mediating autophagy. Circ Res. 2007; 100:914-22.

https://doi.org/10.1161/01.RES.0000261924.76669.36 PMID:17332429

15. Kaludercic N, Maiuri MC, Kaushik S, Fernández ÁF, de Bruijn J, Castoldi F, Chen Y, Ito J, Mukai R, Murakawa T, Nah J, Pietrocola F, Saito T, et al. Comprehensive autophagy evaluation in cardiac disease models. Cardiovasc Res. 2020; 116:483-504. https://doi.org/10.1093/cvr/cvz233 PMID:

16. Przyklenk K, Dong Y, Undyala VV, Whittaker P. Autophagy as a therapeutic target for ischaemia /reperfusion injury? Concepts, controversies, and challenges. Cardiovasc Res. 2012; 94:197-205. https://doi.org/10.1093/cvr/cvr358 PMID:22215722

17. Xie H, Liu Q, Qiao S, Jiang X, Wang C. Delayed cardioprotection by sevoflurane preconditioning: a novel mechanism via inhibiting Beclin 1-mediated autophagic cell death in cardiac myocytes exposed to hypoxia/reoxygenation injury. Int J Clin Exp Pathol. 2015; 8:217-26.

PMID:25755708

18. Lévi F, Okyar A, Dulong S, Innominato PF, Clairambault J. Circadian timing in cancer treatments. Annu Rev Pharmacol Toxicol. 2010; 50:377-421.

https://doi.org/10.1146/annurev.pharmtox.48.113006 .094626 PMID:20055686

19. Kung TA, Egbejimi O, Cui J, Ha NP, Durgan DJ, Essop MF, Bray MS, Shaw CA, Hardin PE, Stanley WC, Young ME. Rapid attenuation of circadian clock gene oscillations in the rat heart following ischemiareperfusion. J Mol Cell Cardiol. 2007; 43:744-53. https://doi.org/10.1016/j.yjmcc.2007.08.018 PMID:17959196

20. Durgan DJ, Pulinilkunnil T, Villegas-Montoya C, Garvey $\mathrm{ME}$, Frangogiannis NG, Michael LH, Chow CW, Dyck JR, Young ME. Short communication: ischemia/reperfusion tolerance is time-of-daydependent: mediation by the cardiomyocyte circadian clock. Circ Res. 2010; 106:546-50.

https://doi.org/10.1161/CIRCRESAHA.109.209346 PMID:20007913

21. Kelleher FC, Rao A, Maguire A. Circadian molecular clocks and cancer. Cancer Lett. 2014; 342:9-18.

https://doi.org/10.1016/j.canlet.2013.09.040

PMID:24099911

22. Fu L, Patel MS, Bradley A, Wagner EF, Karsenty G. The molecular clock mediates leptin-regulated bone formation. Cell. 2005; 122:803-15. https://doi.org/10.1016/i.cell.2005.06.028 PMID:16143109
23. Yi CH, Zheng $\mathrm{T}$, Leaderer $\mathrm{D}$, Hoffman A, Zhu Y. Cancerrelated transcriptional targets of the circadian gene NPAS2 identified by genome-wide ChIP-on-chip analysis. Cancer Lett. 2009; 284:149-56. https://doi.org/10.1016/j.canlet.2009.04.017 PMID: 19457610

24. Clements D, Markwick LJ, Puri N, Johnson SR. Role of the CXCR4/CXCL12 axis in lymphangioleiomyomatosis and angiomyolipoma. J Immunol. 2010; 185:1812-21. https://doi.org/10.4049/jimmunol.0902149 PMID:20585037

25. Wu YT, Tan HL, Huang $Q$, Ong CN, Shen HM. Activation of the PI3K-Akt-mTOR signaling pathway promotes necrotic cell death via suppression of autophagy. Autophagy. 2009; 5:824-34. https://doi.org/10.4161/auto.9099 PMID:19556857

26. Porta C, Paglino C, Mosca A. Targeting PI3K/Akt/mTOR Signaling in Cancer. Front Oncol. 2014; 4:64. https://doi.org/10.3389/fonc.2014.00064 PMID:24782981

27. Englund A, Kovanen L, Saarikoski ST, Haukka J, Reunanen A, Aromaa A, Lönnqvist J, Partonen T. NPAS2 and PER2 are linked to risk factors of the metabolic syndrome. J Circadian Rhythms. 2009; 7:5. https://doi.org/10.1186/1740-3391-7-5 PMID:19470168

28. O’Neil D, Mendez-Figueroa H, Mistretta TA, Su C, Lane $\mathrm{RH}$, Aagaard KM. Dysregulation of Npas2 leads to altered metabolic pathways in a murine knockout model. Mol Genet Metab. 2013; 110:378-87. https://doi.org/10.1016/i.ymgme.2013.08.015 PMID:24067359

29. Garcia JA, Zhang D, Estill SJ, Michnoff C, Rutter J, Reick M, Scott K, Diaz-Arrastia R, McKnight SL. Impaired cued and contextual memory in NPAS2-deficient mice. Science. 2000; 288:2226-30.

https://doi.org/10.1126/science.288.5474.2226 PMID:10864874

30. Partonen T. Clock gene variants in mood and anxiety disorders. J Neural Transm (Vienna). 2012; 119:1133-45.

https://doi.org/10.1007/s00702-012-0810-2 PMID:22538398

31. Kim HI, Lee HJ, Cho CH, Kang SG, Yoon HK, Park YM, Lee SH, Moon JH, Song HM, Lee E, Kim L. Association of CLOCK, ARNTL, and NPAS2 gene polymorphisms and seasonal variations in mood and behavior. Chronobiol Int. 2015; 32:785-91. https://doi.org/10.3109/07420528.2015.1049613 PMID:26134245

32. Kovanen L, Saarikoski ST, Aromaa A, Lönnqvist J, Partonen T. ARNTL (BMAL1) and NPAS2 gene variants 
contribute to fertility and seasonality. PLoS One. 2010;

5:e10007.

https://doi.org/10.1371/journal.pone.0010007

PMID:20368993

33. Smith AK, Fang $\mathrm{H}$, Whistler $\mathrm{T}$, Unger ER, Rajeevan MS. Convergent genomic studies identify association of GRIK2 and NPAS2 with chronic fatigue syndrome. Neuropsychobiology. 2011; 64:183-94. https://doi.org/10.1159/000326692 PMID:21912186

34. Zhu Y, Leaderer D, Guss C, Brown HN, Zhang Y, Boyle P, Stevens RG, Hoffman A, Qin Q, Han X, Zheng T. Ala394Thr polymorphism in the clock gene NPAS2: a circadian modifier for the risk of non-Hodgkin's lymphoma. Int J Cancer. 2007; 120:432-35. https://doi.org/10.1002/ijc.22321 PMID:17096334

35. Hoffman $\mathrm{AE}$, Zheng $\mathrm{T}, \mathrm{Ba} \mathrm{Y}$, Zhu $\mathrm{Y}$. The circadian gene NPAS2, a putative tumor suppressor, is involved in DNA damage response. Mol Cancer Res. 2008; 6:1461-68. https://doi.org/10.1158/1541-7786.MCR-07-2094 PMID:18819933

36. Yuan P, Li J, Zhou F, Huang Q, Zhang J, Guo X, Lyu Z, Zhang $\mathrm{H}$, Xing J. NPAS2 promotes cell survival of hepatocellular carcinoma by transactivating CDC25A. Cell Death Dis. 2017; 8:e2704.

https://doi.org/10.1038/cddis.2017.131

PMID:28333141

37. Corcione A, Ferretti E, Bertolotto M, Fais F, Raffaghello L, Gregorio A, Tenca C, Ottonello L, Gambini C, Furtado G, Lira S, Pistoia V. CX3CR1 is expressed by human B lymphocytes and mediates [corrected] CX3CL1 driven chemotaxis of tonsil centrocytes. PLoS One. 2009; 4:e8485.

https://doi.org/10.1371/journal.pone.0008485 PMID:20041188

38. Ślusarczyk J, Trojan E, Wydra K, Głombik K, Chamera K, Kucharczyk M, Budziszewska B, Kubera M, Lasoń W, Filip $M$, Basta-Kaim A. Beneficial impact of intracerebroventricular fractalkine administration on behavioral and biochemical changes induced by prenatal stress in adult rats: Possible role of NLRP3 inflammasome pathway. Biochem Pharmacol. 2016; 113:45-56.

https://doi.org/10.1016/i.bcp.2016.05.008

PMID:27206338

39. Mizuno T, Kawanokuchi J, Numata K, Suzumura A. Production and neuroprotective functions of fractalkine in the central nervous system. Brain Res. 2003; 979:65-70.

https://doi.org/10.1016/s0006-8993(03)02867-1 PMID: 12850572

40. Stolla $M$, Pelisek J, von Brühl ML, Schäfer A, Barocke V, Heider $P$, Lorenz $M$, Tirniceriu $A$, Steinhart $A$,
Bauersachs J, Bray PF, Massberg S, Schulz C. Fractalkine is expressed in early and advanced atherosclerotic lesions and supports monocyte recruitment via CX3CR1. PLoS One. 2012; 7:e43572.

https://doi.org/10.1371/journal.pone.0043572 PMID:22916279

41. Damås JK, Boullier A, Waehre T, Smith C, Sandberg WJ, Green S, Aukrust P, Quehenberger O. Expression of fractalkine (CX3CL1) and its receptor, CX3CR1, is elevated in coronary artery disease and is reduced during statin therapy. Arterioscler Thromb Vasc Biol. $2005 ; 25: 2567-72$.

https://doi.org/10.1161/01.ATV.0000190672.36490.7b PMID:16224053

42. Richter B, Koller L, Hohensinner PJ, Rychli K, Zorn G, Goliasch G, Berger R, Mörtl D, Maurer G, Huber K, Pacher R, Wojta J, Hülsmann M, Niessner A. Fractalkine is an independent predictor of mortality in patients with advanced heart failure. Thromb Haemost. 2012; 108:1220-27.

https://doi.org/10.1160/TH12-03-0195

PMID:23014777

43. Wu S, Chang G, Gao L, Jiang D, Wang L, Li G, Luo X, Qin S, Guo X, Zhang D. Trimetazidine protects against myocardial ischemia/reperfusion injury by inhibiting excessive autophagy. J Mol Med (Berl). 2018; 96:791-806.

https://doi.org/10.1007/s00109-018-1664-3

PMID:29955901

44. Shi B, Ma M, Zheng Y, Pan Y, Lin X. mTOR and Beclin1: Two key autophagy-related molecules and their roles in myocardial ischemia/reperfusion injury. J Cell Physiol. 2019; 234:12562-68.

https://doi.org/10.1002/jcp.28125 PMID:30618070

45. Huang KY, Wang JN, Zhou YY, Wu SZ, Tao LY, Peng YP, Que JQ, Xue YJ, Ji KT. Antithrombin III Alleviates Myocardial Ischemia/Reperfusion Injury by Inhibiting Excessive Autophagy in a Phosphoinositide 3Kinase/Akt-Dependent Manner. Front Pharmacol. 2019; 10:516.

https://doi.org/10.3389/fphar.2019.00516

PMID:31133861

46. Zhu H, He L. Beclin 1 biology and its role in heart disease. Curr Cardiol Rev. 2015; 11:229-37. https://doi.org/10.2174/1573403×1066614110610460 6 PMID:25373623

47. Ma X, Liu H, Foyil SR, Godar RJ, Weinheimer CJ, Hill JA, Diwan A. Impaired autophagosome clearance contributes to cardiomyocyte death in ischemia/reperfusion injury. Circulation. 2012; 125:3170-81.

https://doi.org/10.1161/CIRCULATIONAHA.111.04181 4 PMID:22592897 


\section{SUPPLEMENTARY MATERIALS}

\section{Supplementary Methods}

\section{Measurement of infarct volume}

Measurement of infarct volumes was performed as previously described.44 In brief, the heart was harvested and rinsed with normal saline. The excised left ventricle was frozen at $-20^{\circ} \mathrm{C}$ for $30 \mathrm{~min}$ and then sectioned from apex to base into $\sim 2-\mathrm{mm}$ slices. The slices were incubated in a solution of $1 \%$ TTC in PBS $\left(\mathrm{pH} \mathrm{7.4)}\right.$ at $37^{\circ} \mathrm{C}$ for $15 \mathrm{~min}$ in darkness and then fixed in $10 \%$ formaldehyde. The slices were photographed the next day using a digital camera. The infarcted (nonTTC-stained) area was isolated from the rest of the cardiac tissue, which was stained red by TTC. The infarct size was expressed as a percentage of the mass of the left ventricle.

\section{Immunohistochemistry}

To measure apoptosis, we fixed and labeled cardiomyocytes or myocardial tissues using TUNEL using a commercially available kit (In Situ Cell Death Detection Kit; Roche Diagnostics, Basel, Switzerland) to label the apoptotic cell nuclei. To identify myocardial tissue damage, we stained myocardial tissues with H\&E. Sections were examined with an Axiophot light microscope (Zeiss, Oberkochen, Germany) and photographed with a digital camera.

\section{Cell transfection}

Cells were transfected with appropriate amount of vector by using Lipofectamine 2000 (Invitrogen, MA, U.S.) and then cultured for 48 hours on the basis of manufacturer's protocol.

\section{Vector construction}

The full-length cDNA of NPAS2 was synthesised by GeneChem (Shanghai, China) and then cloned into the vector. Two shRNAs against NPAS2, Cy2 and CX3CL1, were also synthesized by GeneChem (Shanghai, China). The expression efficiency was examined using qPCR in cells transfected with vector or shRNA.

\section{Flow cytometry assay}

Logarithmically growing podocytes were seeded into culture flasks. The cells were dual stained with Annexin V-FITC and propidium iodide (PI) for $30 \mathrm{~min}$ at room temperature. The stained cells were immediately analyzed by flow cytometry (Becton Dickinson,
Franklin Lakes, NJ, United States). Apoptotic cells were defined as Annexin V-FITC positive and PI negative.

\section{RNA isolation and quantitative real-time PCR}

RNA was isolated using the TRIzol reagent (Invitrogen) according to the manufacturer's instructions in podocytes and mouse kidney samples and reverse transcribed using a miScript Reverse Transcription kit (Qiagen). QRT-PCR was performed using the SYBR Premium Ex Taq II kit (Takara, Dalian, China) in an ABI PRISM 7500 Sequence Detection System (Applied Biosystems). All reactions were performed in triplicate and the mean value was used to calculate expression levels after normalization to $\beta$-actin as an internal standard.

\section{Protein extraction and western blot analysis}

Podocytes were lysed using RIPA buffer, and protein concentration was determined using the BCA protein assay kit. Approximately $30 \mu \mathrm{g}$ of protein from each sample was separated using a 10\% SDS-polyacrylamide gel and transferred to PVDF membranes. Membranes were blocked with 5\% skim milk in TBST and incubated with primary antibodies overnight at $4^{\circ} \mathrm{C}$. Membranes were then incubated with the corresponding secondary antibodies for $1 \mathrm{~h}$ at room temperature and washed in TBST.

\section{Autophagic flux analysis}

Cells transfected with mRFP-GFP-LC3 were fixed with 4\% paraformaldehyde and stained with $10 \mathrm{mM}$ Hoechst 33342. Cell images were obtained using the Operetta High Content Imaging System (Perkin-Elmer) and analyzed using Harmony Analysis Software (PerkinElmer). Cells were analyzed using green (GFP) or red (mRFP) fluorescence. Autophagosomes were stained yellow puncta and autolysosomes stained red puncta in merged images. Autophagic flux was determined by the increased percentage of red puncta in merged images.

\section{Transmission electron microscopy}

Cells were fixed with $2.5 \%$ glutaraldehyde in phosphate buffer and stored at $4^{\circ} \mathrm{C}$ until embedding. Cells were post-fixed with $1 \%$ osmium tetroxide followed by an increasing gradient dehydration step using ethanol and acetone. Cells were then embedded in Araldite, and ultrathin sections were obtained $(50-60 \mathrm{~nm})$, placed on uncoated copper grids, and stained with $3 \%$ lead 
citrate-uranyl acetate. Images were examined with a CM-120 electron microscope (Philips).

\section{Immunoprecipitation}

For immunoprecipitation studies, $5 \mu \mathrm{g}$ of anti-NPAS2 or anti-Cry2 or Rabbit IgG-AC (Proteintech 10746-1AP: Santa Cruz, Dallas, TX, United States, ab37415) was added to cell lysates and incubated overnight at $4^{\circ}$ $\mathrm{C}$, under constant rotation. Immune complexes were precipitated and washed in lysis buffer. Immunoprecipitated samples were subject to western blotting analysis by using anti-acetylation antibody
(Santa Cruz, Dallas, TX, United States, ab51997) and anti-Flag or anti-p65 antibody.

\section{CX3CL1 luciferase reporter assay}

CX3CL1 luciferase reporter assay was performed as described in kits. Briefly, H9c2 cells were transfected with CX3CL1 transcription response element (TRE) containing construct by using lipofectamine 3000 . Luciferase activities were measured using the Duan-Glo Luciferase Assay System, and the constitutively expressed Renilla luciferase was used as an internal control. 